$1-2008$

\title{
The Unsolvable Dilemma of a Paretian Policymaker
}

Giuseppe Dari-Mattiacci

Nuno Garoupa

ngaroup@gmu.edu

Follow this and additional works at: https://scholarship.law.tamu.edu/facscholar

Part of the Law Commons

\section{Recommended Citation}

Giuseppe Dari-Mattiacci \& Nuno Garoupa, The Unsolvable Dilemma of a Paretian Policymaker, 16 Sup. Ct. Econ. Rev. 117 (2008).

Available at: https://scholarship.law.tamu.edu/facscholar/467

This Article is brought to you for free and open access by Texas A\&M Law Scholarship. It has been accepted for inclusion in Faculty Scholarship by an authorized administrator of Texas A\&M Law Scholarship. For more information, please contact aretteen@law.tamu.edu. 


\title{
The Unsolvable Dilemma of a Paretian Policymaker
}

\author{
Giuseppe Dari-Mattiacci ${ }^{*}$ and Nuno Garoupa* *
}

In this paper, we argue that social decision-making is subject to a fundamental conflict between consistency and completeness. We show that a consistent welfarist method of policy assessment, that is, one that never violates the Pareto principle, may be incomplete in the sense that it is incapable of providing a solution to important social welfare problems. Legal policy consequences are discussed.

\section{INTRODUCTION}

Economists argue that important, socially relevant decisions, ranging from merger control to adoption, should be informed by a careful economic analysis. Raising the bar, a prominent view posits that all social decisions should be based exclusively on welfare economics; that is, all other considerations about fairness or justice should be disregarded if they conflict with the maximization of individuals' welfare.

In this paper, we argue that policymaking is subject to a fundamental dilemma, one between consistency and completeness. We

\footnotetext{
*The authors would like to thank Shomu Baneriee, Guilherme Carmona, Antonio Cabrales, Ward Farnsworth, João Gata, David Hoffman, and Jenny Monheim for helpful suggestions. We are particularly grateful to Louis Kaplow for extremely useful critical comments. Nuno Garoupa acknowledges financial support by FCT, POCI/ JUR/55752/2004 and by NWO, B 41-522. The usual disclaimers apply.

Giuseppe Dari-Mattiacci, Amsterdam Center for Law and Economics, Roetersstraat 11, 1018WB Amsterdam, The Netherlands, and Tinbergen Institute, Roetersstraat 31, 1018WB Amsterdam, The Netherlands. Email: gdarimat@uva.nl.

* * University of Illinois College of Law, 504 E Pennsylvania Avenue, Champaign, Illinois 61820, USA. Email: ngaroupa@law.uiuc.edu.
} 
define consistency to mean the implementation of a set of criteria for policy assessment without internal contradictions. In particular, we pay attention to consistency with welfarist evaluation of public policies and therefore with the Pareto principle. We define completeness $^{1}$ to mean the ability of such a set of criteria to assess all relevant policy issues. Consistency does not imply completeness. To the contrary, as we will illustrate, these two goals may in fact conflict. In other words, consistent criteria might not generate a solution to the problem of choosing between two policy outcomes. This point has important implications for public policy because often a choice will have to be made even if welfare economics offers no guidance as to which outcome should be preferred.

Recent literature has focused on the issue of consistency, mostly leaving the problem of completeness without discussion ${ }^{2}$. In particular, Kaplow and Shavell show that any non-welfarist method of policy assessment violates the Pareto principle. ${ }^{3}$ This result implies that if policies are chosen according to criteria that are inconsistent with the welfarist method, the outcome will not maximize social

${ }^{1}$ Completeness refers to complete social preferences and should not be confused with complete individual preferences. Likewise, incompleteness is not to be confused with Arrow's impossibility, which discusses the mutual incompatibility of five basic axioms which a social decision rule should reasonably follow. Our analysis is not restricted by such axioms. Kenneth $\mathrm{J}$. Arrow, Individual Values and Social Choice (Wiley 1951).

${ }^{2}$ See, however, Giuseppe Dari-Mattiacci, Göedel, Kaplow, Shavell: Consistency and Completeness in Social Decision-Making, 79 Chi Kent L Rev 497 (2004) (considering the debate on completeness vs. consistency in mathematics and logic and its implications for welfare economics|. See Efe A. Ok and Levent Koçkesen, Negatively Interdependent Preferences, 17 Social Choice \& Welfare 533 (2000) (concerning the issue of recursivity that will be addressed below in the text). See also Brett McDonnel, Economists' New Argument, 88 Minn L Rev 86 (2003) (addressing the issue of changes in preferences, which will be analyzed later in the text, and noticing that the choice of the criterion concerning how preferences should be shaped involves nonwelfarist considerations). We argue instead that, even if that criterion were entirely welfarist, the recursivity of the logical reasoning needed to assess such policies may ultimately yield no solution to the problem. See also Ward Farnsworth, $A$ Taste for Fairness, 102 Colum L Rev 1992 (2002); Cass R. Sunstein, Legal Reasoning and Political Conflict (Oxford 1996); David A. Hoffman and Michael P. O'Shea, Can Law and Economics Be Both Practical and Principled, 53 Ala L Rev 335 (2002) (which examines the problem of completeness from a different perspective from ours, referring to whether or not economic analysis can be implemented if there is disagreement concerning its validity. See Walter Kanning and Arnald J. Kanning, Book Review: L. Kaplow and S. Shavell: Fairness versus Welfare, 21 Social Choice and Welfare 175 (2003) (which briefly mentions the issue of interdependent preferences discussed further in this article).

${ }^{3}$ Louis Kaplow and Steven Shavell, Any Non-welfarist Method of Policy Assessment Violates the Pareto Principle, 109 J Polit Econ 281 (2001). 
welfare. Consequently, Kaplow and Shavell call for consistency in social decision-making.

In our discussion, we take Kaplow and Shavell's viewpoint on consistency but argue that the welfarist method might not provide a policy assessment when it should. For example, under certain conditions, the welfarist method may be unable to assess non-trivial policies, such as education or freedom of religion, for example, which require the aggregation of individual preferences over a social welfare function. The reason is that, when individuals have preferences over a certain social welfare function, the problem becomes recursive and may either admit no solution or an infinite number of solutions. Therefore, our thesis is not contrary to Kaplow and Shavell's but rather is complementary to it. ${ }^{4}$

In summary, our view is that a consistent welfarist method may be incomplete in the sense that it is incapable of providing a solution to important social welfare problems - thus failing to supply effective policy guidance. If a consistent method is incomplete, a method that guarantees completeness can only be constructed by implementing a set of criteria that allows for some internal inconsistency. As a consequence, there is a potential conflict between consistency and completeness. This potential conflict between consistency and completeness implies that, in many circumstances, social decision-making cannot solely rest on the welfarist method. A complete, social decision-making algorithm may have to take into account those fairness values and more generally the non-individualistic determinants (in the sense of any non-welfarist criterion, as defined in Kaplow and Shavell ${ }^{5}$, which were rejected at the outset because they were inconsistent with the Pareto principle.

Further, we should explain that our article has very little bearing on the controversies generated by Kaplow and Shavell's series of articles. ${ }^{6}$ We do not argue, as some have done, that their analysis is incorrect. ${ }^{7}$ Our claim, instead, is that consistency might come at

\footnotetext{
${ }^{4}$ Also note that our argument is not about why or when recursivity exists, but suggests that recursivity is a limitation to the mathematical formulation of Kaplow and Shavell's consistency criterion. Louis Kaplow and Steven Shavell, Fairness versus Welfare (Harvard 2002).

${ }^{5}$ Id.

${ }^{6}$ Kaplow and Shavell make three arguments. First, they argue that deciding policies on the basis of notions of fairness may violate the Pareto principle. We refer to this point. The authors further argue that notions of fairness may be used as proxies for the Pareto principle and that they may have evolved as rules of thumb for the implementation of the Pareto principle. These arguments are neither discussed nor contested here. Id.

${ }^{7}$ See Howard F. Chang, A Liberal Theory of Social Welfare: Fairness, Utility, and the Pareto Principle, 110 Yale L J 173 (2000); Howard F. Chang, The Possibility of a Fair
} 
the price of incompleteness. In fact, there are situations in which the Paretian method cannot provide a satisfactory answer to the problem of ranking policies, although it satisfies the requirement of consistency set forth by Kaplow and Shavell. ${ }^{8}$

We make no claim about whether a consistent Paretian method should be regarded as the preferable way to assess social policies. This issue was the main focus of the debate between Posner, endorsing the normative use of economics, and Baker, Dworkin, and Kronman, opposing this view. ${ }^{9}$ Kaplow and Shavell address this point and argue that grounding policymaking in criteria that conflict with the Pareto principle ultimately reduces social welfare ${ }^{10}$ However, the authors do not systematically prove that the maximization of social welfare should be the object of policymaking. ${ }^{11}$ Rather, their point on consistency could be applied to any criterion for policymaking. Ultimately, their point is that given a goal for policymaking, the means employed to pursue it should be consistent with that goal. We base our analysis on the assumption that the goal of policymaking is indeed the maximization of social welfare and neither attempt

Paretian, 110 Yale L 251 (2000). For a response, see Louis, Kaplow and Steven Shavell, Notions of Fairness versus the Pareto Principle: On the Role of Logical Consistency, 110 Yale L J 237 (2000). See also Marc Fleurbaey, Bertil Tungodden and Howard F. Chang, Any Non-welfarist Method of Policy Assessment Violates the Pareto Principle: A Comment, 111 J Pol Econ 1382 (2003). For a reply, see Louis Kaplow and Steven Shavell, Any Non-welfarist Method of Policy Assessment Violates the Pareto Principle: A Reply, 112 J Pol Econ 249 (2004). See also Richard Craswell, Kaplow and Shavell on the Substance of Fairness, 32 J Legal Stud 245 (2003); A. Kornhauser, Preferences, Well-being, and Morality in Social Decisions, 32 J Legal Stud 303 (2003); Jeremy Waldron, Locating Distribution, 32 J Legal Stud 277 (2003). For a response, see Louis Kaplow and Steven Shavell, Fairness versus Welfare: Notes on the Pareto Principle, Preferences, and Distributive Justice, 32 J Legal Stud 331 (2003).For a more recent critique, see Arthur Ripstein, Too Much Invested to Quit, 20 Econ \& Phil 185 (2004). For a reply, see Louis Kaplow and Steven Shavell, Notes on Welfarist versus Deontological Principles, 20 Econ \& Phil 209 (2004). See Michael B. Dorff, Why Welfare Depends on Fairness: A Reply to Kaplow and Shavell, 75 S Cal L Rev 847 (2002).

${ }^{8}$ Kaplow and Shavell, 109 J Polit Econ 281 (cited in note 3).

${ }^{9}$ Endorsing the normative use of economics, see Richard A. Posner, Utilitarianism, Economics, and Legal Theory, 8 J Legal Stud, 103 (1979); Richard A. Posner, The Ethical and Political Basis of the Efficiency Norm in Common Law Adjudication, 8 Hofstra L Rev 487 (1980). For an opposing view, see C. Edwin Baker, The Ideology of the Economic Analysis of Law, 5 Phil \& Pub Affairs 3 (1975); Ronald M. Dworkin, Is Wealth a Value? 9 J Legal Stud 191 (1980); Anthony T. Kronman, Wealth Maximization as a Normative Principle, $9 \mathrm{~J}$ Legal Stud 227 (1980). For an extensive reference to this debate, see Kaplow and Shavell, 109 J Polit Econ 281 (cited in note 3).

${ }^{10} \mathrm{Kaplow}$ and Shavell, 32 J Legal Stud 331 (cited in note 7).

"Daniel Farber. What (If Anything) Can Economics Say About Equity, 101 Mich L Rev 1791 (2003). See also Dorff, 75 S Cal L Rev 847 (cited in note 7); Kimberly Kessler Ferzan, Some Sound and Fury from Kaplow and Shavell, 23 L \& Phil 73 (2004). 
to prove nor to disprove this starting point. On the contrary, as to the authors' point on consistency, we believe that our point on completeness also applies more generally and can be extended to any consistent method of policy assessment, even a non-welfarist one.

Some of the contributions following Kaplow and Shavell ${ }^{12}$ are particularly close to ours. Kornhauser makes the point that the aggregation of preferences may be problematic when people have preferences over different 'regimes of rights' ${ }^{13}$ This argument is aimed at unveiling a conflict between potentially inconsistent policy goals. Since individuals might have mutually conflicting preferences, ensuring consistency in the system as a whole might ultimately be impossible. This point is different from the issue of completeness that we discuss. In fact, we show that incompleteness may result in a system where consistency is guaranteed..$^{14}$

Farber emphasizes the fact that the welfarist criterion can be applied only after a social welfare function has been chosen. ${ }^{15}$ This enables the policymaker to aggregate individuals' welfare in a measure of social welfare and hence to choose the policy that maximizes social welfare. Absent a social welfare function, the welfarist criterion cannot be applied. Contrary to Kaplow and Shavell, Farber argues that the choice of the social welfare function can be made only by relying on non-welfarist criteria. Putting it simply, Farber remarks that there may be the need for a starting point, external to welfare economics and in which welfarist analysis can be grounded, reminiscent of the Kelsenian grundnorm. Our point differs in that it applies even if it were possible to use some meta-function to aggregate individuals' preferences over the social welfare function to be chosen. The system is incomplete not because a social welfare function cannot be chosen according to the welfarist criterion, but because problems of recursivity may make it impossible to come to a policy assessment. The choice of a social welfare function is but one example of the set of situations in which this problem might occur.

In the next section, we illustrate our point that welfarism is incomplete for an important class of cases, namely, when recursivity is important. The example we have in mind is that of a computer programmed for ranking public policies according to the welfarist method, thus consistent with the Pareto principle. We ask the com-

${ }^{12}$ Kaplow and Shavell, 109 J Polit Econ 281 (cited in note 3).

${ }^{13}$ Kornhauser, 32 J Legal Stud 303 (cited in note 7 ).

${ }^{14}$ Our analysis is thus also different from Sen, who shows that the Pareto principle and liberal ideals may conflict. Our aim is instead to show that, when a set of consistent criteria is used, some relevant problems may remain unresolved. Amartya Sen, The Impossibility of a Paretian Liberal, 78 J Pol Econ 152 (1970).

${ }^{15}$ Farber, 101 Mich L Rev 1791 (cited in note 11). 
puter to choose between policy A and policy B. Kaplow and Shavell's consistency point is that if we add any non-welfarist constraint into the computer program, the answer provided by the computer might violate the Pareto principle. Our remark is that if the computer is programmed only on the basis of consistent welfarist criteria, it might return the answer 'unable to choose between policy A and policy B.'

Notice that there is a fundamental difference between incompleteness and indifference. The answer returned by the computer could be 'I am indifferent between policy A and policy $\mathrm{B}$, ' and that is not a problem for public policy. Such an answer would simply suggest that the outcomes are equivalent from the point of view of social welfare, and would not imply that the welfarist method is incomplete. In contrast, as we will explain, policies A and B are not equivalent as they yield different levels of social welfare; nevertheless, the computer is unable to say which one is to be preferred. If the aggregate welfare of individuals is to be maximized, adherence to the welfarist method is not a misguided way to ensure the consistent pursue of Pareto efficient policies, as argued by many other scholars; rather, it is an incomplete method.

This example also shows that our point is not about the selection of a social welfare function; that is, the problem is not to decide whether the computer program ought to be a welfarist software. Such a choice points to an endless series of meta-choices of the ultimate criterion to use which in turn would require a series of yet higher-level computers devoted to solve each of these choices. We might have a recursive problem in this case, but of a very different nature from ours. ${ }^{16}$ The problem would be the choice of the appropriate computer software and not, as in our model, the choice of a policy outcome after the computer software has already been implemented. The implications of our findings for public and legal policy are discussed at the end of the paper.

\section{ANALYSIS}

Let $\mathrm{x}$ be a complete description of the world and $n$ the number of individuals, where $x=x_{1}, \ldots, x_{n}$ is a comprehensive account of each individual's situation. Define $X$ to be the set of all conceivable states of the world.

From Kaplow and Shavell ${ }^{17}$, we can make the following statements:

${ }^{16}$ This is the line of reasoning by Farber, 101 Mich L Rev 1791 (cited in note 11).

${ }^{17}$ Kaplow and Shavell, 109 J Polit Econ 281 (cited in note 3). 
(1) A social welfare function $F$ is a function from $X$ to the real line $\Re$.

(2) An individual utility function $U_{i}$ for each $i=1, \ldots, n$ is also a function from $X$ to $\Re$.

(3) An individualistic social welfare function is a social welfare function of the form $F\left(U_{1}(x), \ldots, U_{n}(x)\right)$.

(4) A social welfare function is not individualistic if and only if there exist $x, x^{\prime} \in X$ such that $\left.U_{i}(x)=U_{i} \mid x^{\prime}\right)$ for all $i$ and $F(x) \neq F\left(x^{\prime}\right)$.

(5) The weak Pareto principle is that if, for any states $x, x^{\prime} \in X$, we have $U_{i}(x)>U_{i}\left(x^{\prime}\right)$ for all $i=1, \ldots, n$, then $F(x)>F\left(x^{\prime}\right)$.

(6) If a social welfare function ascribes weight to some factor independently of its effect on individuals' utilities in a non-individualistic way, then that social welfare function violates the Pareto principle. ${ }^{18}$

Therefore, we now have a consistent method to evaluate policies and that respects the Pareto principle. Any method that does not respect a welfarist approach violates the Pareto principle.

Suppose now that $F$ is of the form $F\left(U_{1}(x), \ldots, U_{n}(x)\right)$ and $U_{i:} \rightarrow \Re$ is of the form $U_{i} \mid x, F($.$) for all i=1, \ldots, n$. Following the reasoning of Bergstrom $^{19}, U_{i}$ is an interdependent utility function such that individual $i$ 's preferences depend on his own situation but also on societal welfare.$^{20}$ Then for any state of the world $x$ it must be true that $F=F\left(U_{i}\right.$ $(x, F()$.$) . We are interested in whether a system of interdependent pref-$ erences resolved by private subutility of $x$ and interdependent social welfare determines a corresponding system of independent utility functions $V_{i:} \rightarrow \Re$ and an independent social welfare function $G(x)$. Unfortunately, a general answer to recursive social welfare functions is not easy to find. ${ }^{21}$ Notice that if such an independent social welfare function exists, we have consistency (with the Pareto principle) and completeness. Our point is of course that such a function might not exist. Therefore, although we have consistency, we do not have completeness (because it will not provide us with a complete ranking of social outcomes). ${ }^{22}$

${ }^{18}$ Proof in Kaplow and Shavell, 109 J Polit Econ 281 (cited in note 3).

${ }^{19}$ Theodore C. Bergstrom, Systems of Benevolent Utility Functions, $1 \mathrm{~J}$ Pub Econ Theory 71 (1999).

${ }^{20}$ The original terminology derives from Pollak. Robert A. Pollak, Interdependent Preferences, 66 Am Econ Rev 309 (1976). Bergstrom studies interdependent utilities when individual $A$ cares for individual $B$ and vice-versa, and not social preferences. Bergrstrom, $1 \mathrm{~J}$ Pub Econ Theory 71 (cited in note 19)

${ }^{21}$ Bergrstrom, $1 \mathrm{~J}$ Pub Econ Theory 71 (cited in note 19); Yann Bramoullé, Interdependent Utilities, Preference Indeterminacy, and Social Networks, U Md (unpublished manuscript 2001).

${ }^{22}$ Although it is possible that Kaplow and Shavell's mathematical formulation refers to independent utilities, it does not exclude inter-dependent utilities. Kaplow and Shavell, 109 J Polit Econ 281 (cited in note 3). 
As an illustration, assume that $U_{i}(.) \rightarrow \Re$ is an interdependent utility with an additively separable form (a Bergstrom-interdependent utility function):

$$
U_{i}(x, F(.))=u_{i}(x)+\alpha_{i} F(.)
$$

where $u_{i}(x)$ is the private subutility of $x$ satisfying the usual assumptions and $\alpha_{i}$ is constant and exogenous. ${ }^{23}$

Let us also assume that social welfare is a weighted utilitarian function, such that:

$$
F=\sum_{i=1}^{n} \beta_{i} U_{i}(.)=\sum_{j=1}^{n} \beta_{i} u_{j}(x)+F(.) \sum_{i=1}^{n} \beta_{i} \alpha_{i}
$$

where $\beta_{j}$ is exogenous. ${ }^{24}$

The independent social welfare satisfies Kaplow and Shavell's mathematical conditions and can be derived as:

$$
G\left(u_{1}(x), \ldots, u_{n}(x)\right)=\frac{\sum_{i=1}^{n} \beta_{i} u_{i}(x)}{1-\sum_{j=1}^{n} \beta_{i} \alpha_{j}}
$$

The independent utility function of individual $i$ is given by:

$$
V_{i}(x)=u_{i}|x|+\alpha_{i} \frac{\sum_{i=1}^{n} \beta_{i} u_{i}|x|}{1-\sum_{i=1}^{n} \beta_{j} \alpha_{i}}=\frac{1-\sum_{i \neq i}^{n} \beta_{j} \alpha_{i}}{1-\sum_{i=1}^{n} \beta_{j} \alpha_{i}} u_{i}(x)+\alpha_{i} \frac{\sum_{i \neq i}^{n} \beta_{i} u_{i}|x|}{1-\sum_{i=1}^{n} \beta_{i} \alpha_{i}}
$$

There are three possible situations to be considered:

(1) $\sum_{j=1}^{n} \beta_{j} \alpha_{j}<1$ : there is a unique solution to the problem of finding an independent social welfare function. This corresponds to the usual assumption taken in the altruism literature. ${ }^{25}$ This is a situation where welfarism is consistent and complete.

${ }^{23}$ Preferences can be positively interdependent or negatively interdependent. See Ok and Koçkesen, 17 Social Choice \& Welfare 533 (cited in note 2). We do not impose any restriction on the sign of $\alpha_{i}$.

${ }^{24}$ The indeterminacy problem discussed by Farber is with respect to $\beta_{i}$ for $j=1$ to $n$. Notice once again that our quest is different from that paper, since in our analysis $\beta_{i}$ is well-defined but exogenously determined. Farber, 101 Mich L Rev 1791 (cited in note 7).

${ }^{25}$ Gary Becker, A Theory of Social Interactions, 82) Polit Econ 1063 (1974); D. Bernheim and O. Stark, Altruism Within the Family Reconsidered: Do Nice Guys Finish Last?, 78 Am Econ Rev 1034 (1988); Bergstrom, 1 I Pub Econ Theory 71 (cited in note 19|; Roger Bowles and Nuno Garoupa, Household Dissolution, Child Care and Divorce Law, 22 Intl Rev L \& Econ 495 (2002). 
(2) $\sum_{j=1}^{n} \beta_{j} \alpha_{j}>1$ : the solution we have derived is unstable. According to Bramoullé, the reasonable economic interpretation of instability should be that there is an infinite solution set to the problem of finding an independent social welfare function. A related interpretation is discussed by Postlewaite. ${ }^{26}$ Nevertheless it is not the case that all solutions yield the same level of social welfare. Clearly other social criteria are required to help a welfarist analysis in this situation since policymaking requires a choice and the implementation of a determined policy.

$(3) \sum_{j=1}^{n} \beta_{i} \alpha_{j}=1$ : there is no solution to the problem of finding an independent social welfare function. A welfarist analysis in this situation does not identify the optimal policy, and yet policymaking requires that some policy is chosen and implemented.

Hence, from this example, it is clear that if we live in a world described by (2) or (3) a welfare analysis is consistent but incomplete. Notice that imposing restrictions on the parameters to make sure we are in (1) is not an acceptable solution since these are exogenous parameters determined by individual preferences and the available mechanisms to determine a specific social welfare function. In fact, ad-hoc restrictions would be non-welfarist and therefore inconsistent. $^{27}$

\section{IMPLICATION S}

Kaplow and Shavell argue that policies should be chosen according to the welfarist criterion and also suggest that, when individual preferences depend on policies, the most desirable policy can be found by means of the welfarist analysis. ${ }^{28}$ We have argued that this may not be the case, because a consistent welfarist method of policy assessment may be incomplete, that is, unable to provide answers to important policy issues, such as the aggregation of individual preferences in a social welfare function and the way policies shape preferences. It is not our claim that the welfarist method is always incomplete but

${ }^{26}$ Andrew Postlewaite, The Social Basis of Interdependent Preferences, 42 Eur Econ Rev 779 (1998). Notice also that the literature (Becker, Bernheim and Stark) discard this possibility because the independent utility function is decreasing in consumption. Becker, 82 J Polit Econ 1063 (cited in note 25); Bernheim and Stark, 78 Am Econ Rev 1034 (cited in note 25).

${ }^{27}$ It would be as arguing that because we want consistency and completeness we can only live in world (1).

${ }^{28}$ Kaplow and Shavell, 32 J Legal Stud at 413-18 (cited in note 7). 
rather than it will be incomplete for a subgroup of possible but important cases.

We believe that many policy areas, in particular legal policy, are characterized by this problem as a consequence of, for example, recursivity. These issues include questions concerning equality, liberty, distribution of resources, multicultural integration, education of youth, and re-education of criminals.

Our viewpoint is that trying to solve these problems by use of the welfarist method may lead to a circular and therefore inconclusive reasoning. It is evident that society cannot generally afford to let such fundamental questions go unanswered. The only way out is resorting to precisely those criteria that give independent weight to values other than individual welfare, that is, precisely those criteria that are considered notions of fairness in Kaplow and Shavell's analysis. Eventually a non-welfarist method might have to be used when a consistent welfarist method is unable to provide an answer. 